\title{
Princípios da Performance Pedagógica dos Tutores da $\mathrm{UAB} / \mathrm{UFSM}$
}

\section{Principles of the Pedagogical Performance of UAB/ UFSM Tutors}

\author{
ROGÉRIO TUBIAS SCHRAIBER \\ Universidade Federal de Santa Maria \\ ELENA MARIA MALLMANN \\ Universidade Federal de Santa Maria
}

Resumo: Com foco na tutoria no ensino superior a distância, realizamos um estudo da Performance Pedagógica dos Tutores da Universidade Aberta do Brasil na Universidade Federal de Santa Maria, cujo objetivo é a identificação dos princípios que embasam sua Performance Pedagógica. A base teórica está centrada nos Estudos da Performance e na Performance Docente. Os procedimentos metodológicos são exploratório-explicativos, inseridos em um estudo desenvolvido entre 2016 e 2017, com uso de questionários, observações e uma entrevista. A Análise Textual Discursiva orientou a análise dos dados em três etapas: unitarização, categorização e novo emergente. Como resultado, apontamos três categorias emergentes dos dados: a Fluência Tecnológico-Pedagógica, a Invenção Pedagógica e a Interação. Conclusivamente, afirmamos essas categorias como princípios da Performance Pedagógica dos Tutores que potencializam e embasam o Processo Ensino-Aprendizagem com transformação, intervenção e produção de conhecimento.

Palavras-Chave: Performance Pedagógica. Fluência Tecnológico-Pedagógica. Invenção. Interação. Tutoria.

\begin{abstract}
With a focus on tutoring in distance higher education, we conducted a study of the Pedagogical Performance of the Tutors of the Universidade Aberta do Brasil at the Universidade Federal de Santa Maria, whose objective is to identify the principles that underpin its Pedagogical Performance. The theoretical basis is centered on Performance Studies and Teaching Performance. The methodological procedures are exploratory-explanatory, inserted in a study developed between 2016 and 2017, with the use of questionnaires, observations and an interview. The Discursive Textual Analysis guided the data analysis in three stages: unitarization, categorization and emerging new. As a result, we have identified three emerging categories of data: Technological-Pedagogical Fluency, Pedagogical Invention, and Interaction. Conclusively, we affirm these categories as principles of Pedagogical Performance of Tutors that potentiate and base the Teaching-Learning Process with transformation, intervention and production of knowledge.
\end{abstract}

Keywords: Pedagogical Performance. Technological-Pedagogical Fluency. Invention. Interaction. Tutoring. 


\section{Introdução}

Estabelecer mediação entre professores, estudantes, conteúdos e materiais didáticos por meio das Tecnologias Educacionais em Rede (TER) é papel do tutor na Educação a Distância (EAD). No contexto da Universidade Aberta do Brasil (UAB), na Universidade Federal de Santa Maria (UFSM), a Performance Pedagógica dos Tutores (PPT) acontece pelas TER, mais precisamente pelo Ambiente Virtual de Ensino-Aprendizagem (AVEA) Moodle1. Diante disso, enfatizamos a necessidade de os tutores possuírem fluência com as tecnologias para que possam mediar o Processo Ensino-Aprendizagem (PEA) por intermédio desse AVEA.

Para identificarmos os princípios da Performance Pedagógica de um grupo de tutores da UAB/UFSM, dispomos, como fundamentação teórica, dos Estudos da Performance e das pesquisas em torno da Performance Docente de Mallmann (2008), que apontam para desdobramentos dos Estudos da Performance nos contextos educacionais. Nossa pesquisa é um estudo que integra procedimentos metodológicos exploratório-explicativos, baseados em questionários online, observações e entrevista, amparados pelo modelo analítico da Análise Textual Discursiva (MORAES; GALIAZZI, 2013), composto pelas fases de unitarização, categorização e novo emergente. Os dados levantados nas observações e nos questionários aplicados a 16 tutores de três cursos, em nível de Especialização, da UAB/UFSM (Gestão de Arquivos, Eficiência Energética Aplicada a Processos, e Tecnologias da Informação e da Comunicação Aplicadas à Educação), entre 2016 e 2017, resultaram em três categorias: a Fluência Tecnológico-Pedagógica (FTP), a Invenção Pedagógica e a Interação, as quais consideramos princípios da PPT na UAB/UFSM.

Apresentamos, no decorrer do texto, o conceito de performance e suas relações com a Educação; expomos o procedimento metodológico e o espaço de pesquisa; discutimos os resultados a partir das três categorias, cada uma alicerçada em sua base teórica. Concluímos, afirmando que a FTP, a Invenção Pedagógica e a Interação estão imbricadas entre si e potencializam a PPT que, assim, intensifica o desenvolvimento do PEA com transformação, intervenção e produção de conhecimento.

\section{Estudos da Performance: base epistemológica}

A palavra 'performance' origina do verbo inglês to perform e seus significados compreendem realizar, completar e executar, sendo mais conhecido por desempenho, façanha, atuação, rendimento, função ou espetáculo (SCHRAIBER; MALLMANN, 2018). Na Arte, a performance corresponde a uma manifestação híbrida que combina várias linguagens artísticas, mas o significado que atribuímos à performance em nossos estudos vai além de uma manifestação artística ou de um simples desempenho. No contexto educacional, entendemos a performance como o movimento de ação-reflexão-ação, envolvendo teoria e prática. Portanto, não é um simples desempenho, mas o que constitui o pensar e o fazer, a relação entre teoria e prática, respectivamente. É o desenvolvimento de um conjunto de ações e estratégias pedagógicas que integram o movimento de ação-reflexão-ação, fazendo o PEA aconteçer. É o papel dos

\footnotetext{
1 Modular Object-Oriented Dynamic Learning Environment/ Ambiente de Aprendizagem Dinâmico Orientado a Objetos.
} 
profissionais da Educação, como professores e tutores, estando aí incluído o modo como estes conduzem e promovem o PEA. Por isso, é performance pedagógica, porque é realizada nesse contexto e por esses profissionais, não por outros.

Após o estudo de Mallmann (2008), começam a ganhar espaço no início do século XXI, em nosso país, pesquisas a respeito da relação entre performance e educação. No entanto, o caráter multifacetado da palavra performance já vem há algum tempo aguçando o interesse de pesquisadores de diversas áreas, como das Ciências Sociais, da Antropologia, da Filosofia, da Etnografia, da Linguística, da Psicologia, da Arte e dos Estudos Culturais, constituindo o campo interdisciplinar dos Estudos da Performance, cujo pioneirismo é atribuído à Richard Schechner, a partir dos anos de 1950 (SALGADO, 2014). Os Estudos da Performance apresentam uma grande variedade de possibilidades nas quais a performance é como um instrumento pelo qual "é possível pensar as relações sociais, as políticas públicas, as identidades de gênero e de raça, a estética, a infância, o currículo, os rituais, a vida cotidiana" (ICLE, 2013, p.15-16).

Ao estabelecer relações mais diretas entre performance e Educação, Mallmann (2008) trata do mapeamento das especificidades da performance docente na produção de materiais impressos e hipermidiáticos e suas implicações na potencialidade da mediação pedagógica em EAD, em sua tese. Para tanto, elegeu os princípios da competência, da autonomia e do desejo, originados dos dados produzidos em sua pesquisa, como propulsores da performance docente.

Em 2010, a Revista Educação \& Realidade (Faculdade de Educação da Universidade Federal do Rio Grande do Sul) publica o dossiê Performance, Performatividade e Educação, com 8 artigos sobre a performance em perspectivas educacionais, sendo um destes uma entrevista com Richard Schechner, que afirma que a Educação não deve ser apenas um comportamento passivo, no sentido de apenas receber informações prontas, mas "precisa ser ativa, envolver num todo mentecorpoemoção - tomá-los como uma unidade. Os Estudos da Performance são conscientes dessa dialética entre a ação e a reflexão" (SCHECHNER; ICLE; PEREIRA, 2010, p. 26).

Outra tese, a de Conte (2012), discute o conceito de performance que permanecia submetido a uma racionalidade instrumental e objetivista, o que incidia na pedagogização de processos de formação e na condução de uma educação tecnicista. Essa pedagogização transforma a Educação em um sistema técnico e administrativo, pois remete a propostas de uniformização de treinos técnicos para o exercício e a repetição (sem qualificação para a ação), e de reprodução (não da construção).

Pereira (2013) organiza 14 artigos com diferentes abordagens metodológicas, mostrando a Educação como um campo com muito a oferecer aos Estudos da Performance. Em 2014, a Revista Educação (Centro de Educação/UFSM) lança o dossiê Performance e Educação, com 6 artigos sobre relações entre performance e Educação. Jacques (2014), em sua dissertação, aborda a performance da Equipe Multidisciplinar da UAB/UFSM, em relação às ações de pesquisa, desenvolvimento e capacitação para a produção de materiais didáticos hipermidiáticos no Moodle. Em 2017, os Cadernos CEDES publicam um conjunto de 8 artigos sobre questões particulares da escola sob a perspectiva da performance. Jacques (2017) discute, em sua tese, a performance docente como potencializadora de atos éticos e estéticos 
na (co)autoria de recursos educacionais abertos, quando promove a superação da consciência ingênua e fortalece a formação da consciência crítica. Além disso, ainda há alguns artigos que discutem a performance docente no PEA por meio das TER, como as produções de Mallmann e Catapan (2010), Mallmann et al. (2013) e Mallmann e Jacques (2014; 2015).

Essas pesquisas nos embasam para desdobramentos da performance na tutoria como possibilidade de ação, transformação e intervenção na Educação. Segundo Mallmann e Jacques (2014, p. 57), "a performance é uma ação expressiva que não representa o mundo, mas sim o pronuncia". Performance é ação que, no PEA, é educativa, portanto, é pedagógica. A "ação educativa abrange, aqui, prática pedagógica e processo de ensino e aprendizagem" (PEREIRA, 2012, p. 290), sendo uma "ação performativa, de abertura de horizontes, de possibilidades" (CONTE, 2012, p.16). O conceito de performance é sempre associado com o princípio da prática investigativa, não como sendo improviso, "mas trabalho docente alicerçado em planejamento e avaliação contínua. [...] é uma forma de identidade, pois é constitutiva" tanto das ações de ensinar-aprender como do/a docente (JACQUES, 2017, p. 75). A performance é um "ato de invenção, criação de situações que induzam os/as estudantes à aprendizagem", é "algo socialmente situado, responsável, responsivo e criador", tendo "de ser produção ética e estética, e não reflexo da reprodução fabril (JACQUES, 2017, p. 76-82).

Para Icle (2013, p. 19), a performance abre a possibilidade de uma experiência nova na qual a oportunidade de romper os estereótipos é sempre evidente e, ao entendê-la como uma experiência coletiva, a performance "é ação no mundo" que gera uma "força motora capaz de intervir para transformar" (MALLMANN; JACQUES, 2014, p. 57), e amplia "a relação com o mundo, oferece mais informações e intensifica as possibilidades de obter solução para os conflitos" (CONTE, 2012, p.77).

A PPT vai se alicerçando conforme o tutor vai adquirindo autonomia durante o desenvolvimento de estratégias pedagógicas, integradas às TER, para solução de problemas de aprendizagem. É na invenção dessas estratégias que a PPT acontece. A criatividade, a curiosidade, o interesse, os materiais didáticos, o conhecimento e a tecnologia são referenciais necessários para essa invenção, pois "conhecer e avaliar as ferramentas tecnológicas disponíveis, saber quais, como e quando integrá-las na mediação [...] são conhecimentos básicos" (MALLMANN; JACQUES, 2014, 58) para o tutor em sua Performance Pedagógica.

De acordo com Mallmann (2008, p. 22), "a performance docente diz respeito ao trabalho docente", então, ao estudarmos o trabalho dos profissionais da Educação, sejam eles professores ou tutores, estamos estudando como são suas performances no PEA. Embora professores e tutores tenham funções diferentes, suas performances são pedagógicas, pois ambos estão inseridos no PEA. Um professor, quando ensina, "precisa definir relações com os estudantes, precisa desempenhar o papel do professor" (SCHECHNER; ICLE; PEREIRA, 2010). Este papel, considerando, ainda, que o tutor também possui o seu, é o que chamamos de Performance Pedagógica que, na EAD, é realizado por meio das TER, envolvendo o desenvolvimento de:

competências para transposição de saberes lançando mão das possibilidades da hipermídia para gerar ensino-aprendizagem. Tais competências são habilidades contemporâneas, conhecimentos sobre os conceitos fundamentais 
da integração das tecnologias na educação e desenvolvimento de capacidades intelectuais para criação e compartilhamento de inovações pedagógicas através das tecnologias (MALLMANN; JACQUES, 2014, p. 50).

Com essas competências, a Performance Pedagógica possibilita pensar a prática educativa como invenção, como um modo de fazer e não como conhecimento acabado, sendo sempre uma produção de si e dos outros (ICLE, 2013). Assumir a performance na tutoria significa entendê-la como "ato de invenção, criação de situações que induzam os estudantes à aprendizagem" (JACQUES, 2014, p. 66). A performance faz o tutor pensar a tutoria com Invenção Pedagógica, originando formas renovadas de Interação, não somente entre conhecimentos, saberes, informações, mas entre sujeitos, papéis, personagens, ideias, espaços e tempos (ICLE, 2013).

Na EAD, os conteúdos curriculares são definidos pelos professores, mas as estratégias que os tutores desenvolvem para produzir conhecimento com esses conteúdos e o modo como as implementam constituem a Performance Pedagógica e isso é um processo de Invenção Pedagógica, cuja complexidade "consiste na efetivação da mediação pedagógica através das tecnologias educacionais em rede" (MALLMANN et al., 2013, p. 310). Em nossos estudos, vemos a PPT como um processo que:

\begin{abstract}
se complexifica na medida em que são requeridas aquisição e aprimoramento de fluência nas tecnologias educacionais. [...] caracteriza-se como ação complexa pelo fato de que é necessário desenvolver aptidões e conhecimentos para organizar e direcionar a prática pedagógica. [...] é um processo complexo porque requer o desenvolvimento de fluência ao longo da vida, com ações contínuas de aperfeiçoamento através da amplificação de novos conhecimentos, habilidades e capacidades para lidar com as tecnologias em rede (MALLMANN et al., 2013, p.314-318-326).
\end{abstract}

No PEA via tecnologia, a PPT se instaura como uma "ação modificadora e transformadora à medida que se movimenta em direção às possibilidades inovadoras de (re)criação de práticas educativas" (MALLMANN; JACQUES, 2015, p. 53), sendo a transformação uma ação necessária à PPT. Ainda, conforme essas autoras, "a performance é intervenção no processo ensinoaprendizagem, a qual requer ir além do saber fazer: implica saber ser. Diante disso, não é mero desempenho [...]. A performance como intervenção modificadora é, por si só, uma ação complexa" (MALLMANN; JACQUES, 2015, p. 55 e 56).

A seguir, apresentamos o procedimento metodológico com o qual realizamos nossos estudos da PPT da UAB/UFSM.

\title{
3 Encaminhamento metodológico
}

O sistema UAB, espaço desta pesquisa, foi instituído pelo Decreto 5.800 , de 8 de junho de 2006. É uma política pública para ampliação e interiorização do ensino superior a distância no Brasil, gerenciada pela Coordenação de Aperfeiçoamento de Pessoal de Nível Superior (CAPES), em convênio com Instituições Públicas de Ensino Superior (IES) e em colaboração com entes federativos que mantêm os polos presenciais. Os cursos da UAB/UFSM priorizam a mediação inovadora das tecnologias, especialmente dos AVEA, que, na UFSM, é o Moodle (MALLMANN et al., 2011). 
Desenvolvemos esta pesquisa estudando um grupo de tutores dos três cursos de pósgraduação anteriormente citados, no que se refere ao fenômeno da Performance Pedagógica, dos respectivos tutores mediada por TER no ensino superior a distância. Nesse contexto, nos detemos na identificação dos princípios que embasam a PPT. Para tanto, estabelecemos os alguns procedimentos metodológicos.

Em primeiro, contatamos as coordenações de cursos solicitando permissão para interagirmos com seus tutores, sendo que 16 aceitaram participar da pesquisa. Esse grupo era formado por 6 tutores e 10 tutoras. A idade variava entre 27 e 50 anos. Alguns já pósgraduados e outros pós-graduandos. A pós-graduação é requisito para ser tutor na UAB/UFSM.

Em segundo momento, implementamos dois questionários online como instrumentos de produção de dados. O primeiro, em 2016, dividido em duas partes, sendo a primeira, com 11 questões sobre informações gerais do tutor. A segunda parte, com 15 questões mais específicas sobre o conhecimento acerca da função de tutoria. O segundo questionário, em 2017, envolveu 28 questões mais focadas no desenvolvimento da tutoria e na integração de tecnologias. Além dos questionários, observamos reuniões de tutoria. Durante essas observações, acompanhamos o diálogo dos tutores, anotamos falas e depoimentos sobre o cotidiano da tutoria dos referidos cursos. Realizamos, ainda, uma entrevista semi-estruturada, estabelecendo uma conversa com cada tutor entrevistado, a partir de sua experiência na tutoria de modo que falassem livremente e, assim, lançamos novas perguntas.

Em terceiro, analisamos os dados obtidos, o que entendemos como uma tarefa complexa, sem procedimento específico, e o pesquisador necessita trabalhar com intuição, desenvolvendo uma organização sem vinculação com modelos estabelecidos (GIL, 2009). Desse modo, estudamos as informações obtidas no sentido de compreendermos o modo como acontece a performance dos tutores.

Utilizamos a Análise Textual Discursiva por ser um processo auto-organizado em que novos significados surgem a partir de três componentes ordenados: a unitarização, correspondendo a desconstrução do corpus dos dados em várias unidades; a categorização, correspondendo ao agrupamento das unidades em categorias; e o novo emergente que trata da nova compreensão que é comunicada e validada em forma de metatexto (MORAES; GALIAZZI, 2013). A Análise Textual Discursiva nos permitiu, na fase da unitarização, elencar diversas unidades (palavras ou frases) que, de acordo com o assunto em comum, na categorização, foram subdivididas em três grupos maiores, denominados de Fluência Tecnológico-Pedagógica (FTP), de Invenção Pedagógica e de Interação, ou seja, as categorias da pesquisa que resultaram no novo emergente. Portanto, essas categorias não são pré-estabelecidas, pois emergem dos dados produzidos, nos auxiliando na identificação dos princípios da PPT da UAB/UFSM, conforme veremos a seguir.

\section{Resultados e discussões}

\subsection{Fluência Tecnológico-Pedagógica (FTP)}

Como a EAD se dá pelas TER, o conhecimento sobre a tecnologia e sobre o modo como integrá-la com o pedagógico é fundamental. O tutor necessita desenvolver FTP, conciliando a 
fluência tecnológica com a pedagógica. A fluência tecnológica "refere-se ao tipo de conhecimento que o tutor precisa ter sobre a tecnologia educacional para interagir e resolver problemas nas variadas situações de ensino-aprendizagem" (MALLMANN et al., 2011, p. 08). Um conceito mais amplo trata a FTP como:

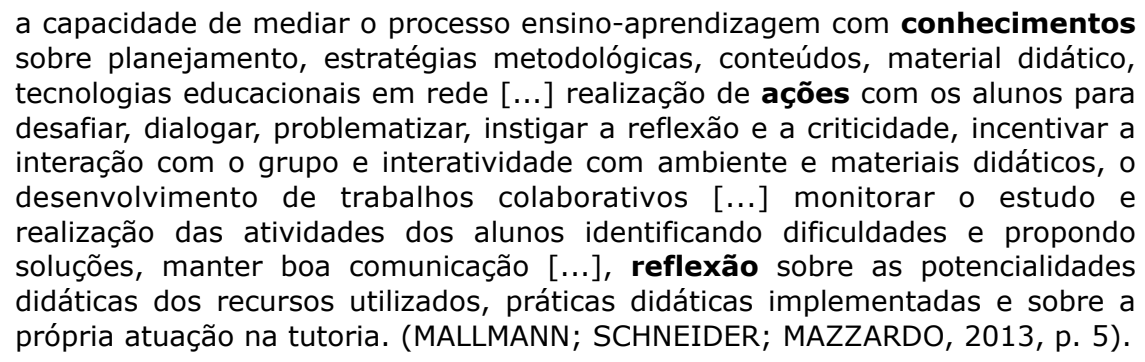

A fluência tecnológica está em função da pedagógica, de modo que uma complementa a outra. Não são isoladas e não ocorre uma após a outra, mas simultaneamente, o que permite unir ambos os conhecimentos, por isso é tecnológico-pedagógica.

A EAD se coloca como uma oportunidade à inserção de tecnologias no PEA, na interação entre professores, tutores, estudantes e conteúdos (MALLMANN et al., 2013). Desse modo, vemos a EAD como o lócus de uma Performance Pedagógica que, apoiada na FTP, encontra potencial para um ensino-aprendizagem inovador, pois, sendo fluente, o tutor consegue integrar tecnologias. Corrêa (2005, p.14) ressalta que as tecnologias "podem e devem contribuir para a melhoria do indivíduo, neste caso, em especial, para o processo ensinoaprendizagem da sociedade contemporânea". A Performance Pedagógica surge, então, como uma possibilidade às necessidades dessa sociedade.

Os tutores relataram que elaboram tutoriais explicativos, planilhas no Google Drive, para avaliações de atividades, e integram vídeos do Youtube como recursos tecnológicos. Com a elaboração dessas estratégias, desenvolvem a FTP e, também, a Invenção Pedagógica e a Interação, potencializando o PEA. Discutiremos mais sobre essas estratégias na próxima categoria.

Nos seguintes depoimentos, vemos a necessidade da FTP: "Estou sempre em busca de novos aplicativos e novas plataformas, inclusive dou cursos sobre diversos recursos digitais que são utilizados em ensino e aprendizagem"; "Contudo, acredito que as tecnologias surgem muito rapidamente, assim, implica que devemos estar constantemente nos capacitando para seu uso"; e "Já faz tempo que trabalho no Moodle, mas é preciso se atualizar a cada momento, pois sempre tem algo novo surgindo". Com base nas observações das reuniões de tutoria nos questionários e na entrevista, selecionamos os seguintes trechos de falas e respostas que reafirmam a necessidade da FTP como princípio da tutoria:

\footnotetext{
"Saber trabalhar com esse aluno que ta online. Ele ta online, mas não pode ficar distante".

"...usar todos os recursos possíveis para sanar dúvidas".

"...buscar vídeos, textos, outros recursos".

"Indico vídeos do youtube [...] crio tutoriais e passo-a-passo com foto, com print screan de tela".

"Possuir instruções referentes ao Moodle, pois o tutor precisa dominar essa ferramenta".
} 
"Saber usar o Moodle corretamente [...] domínio das principais ferramentas da Internet".

"Tem que ter o letramento necessário. Conhecer a plataforma".

"...uso de novas ferramentas pelo tutor, praticar o uso de uma tecnologia".

"Ter domínio da tecnologia [...] possuir o conhecimento da plataforma digital, conhecimento de informática".

"...considero muito importante a realização de cursos, que deveriam ser ofertados [...] com intuito de "reciclar os tutores", estimulando e melhorando a fluência tecnológica dos tutores".

"...incluir outros aplicativos de interação social."

Com base nisso, podemos afirmar que a articulação entre os conhecimentos tecnológico e pedagógico é necessária aos tutores, pois possibilita a Invenção Pedagógica, auxiliando na produção de conhecimento e na resolução de problemas de aprendizagem. Em consonância, outros tutores, respectivamente, afirmaram que "a partir do momento em que o tutor domina as diferentes tecnologias, ele consegue ter uma visão mais ampla sobre como e quando utilizálas para fins educacionais"; e que "um tutor que não tem uma boa fluência tecnológica, com certeza, não conseguiria proporcionar aos alunos novos métodos de aprendizagem". Cabe salientar que alguns tutores já atuaram em Cursos de Capacitação de Tutores na UAB/UFSM, nos quais a FTP é conteúdo estudado, desse modo, para esses, a relação com a necessidade da FTP na tutoria é mais direta, tanto que mencionaram nas suas respostas.

A integração de tecnologias que vemos nos relatos, além do domínio do Moodle, indica que os tutores estão desenvolvendo a FTP que se mostra, então, como uma condição básica para o desenvolvimento da PPT. Isso indica que os tutores vêm adquirindo o conhecimento de que "diante das transformações tecnológicas do nosso tempo e da ubiquidade de novas mídias, o desenvolvimento de competências e habilidades nesta área é visto como primordial" (AMARAL; AMIEL, 2013, p. 03).

As habilidades e a exploração das possibilidades de invenção da tecnologia são potencializadas conforme conhecimento tecnológico e pedagógico é desenvolvido e vice-versa, pois a FTP e a Invenção Pedagógica estão fortemente conectadas. Isso agrega conhecimentos, fazendo a performance adquirir potência como processo complexo e contínuo, na medida em que os tutores se desafiam na invenção de estratégias cada vez mais criativas que as anteriores, com as condições dadas pelas tecnologias.

\subsection{Invenção Pedagógica}

A tecnologia trouxe inovação e invenção à Educação. Por Invenção Pedagógica entendemos a elaboração de estratégias pedagógicas, envolvendo tecnologias, que potencializam o PEA e fazem o tutor pensar as dificuldades de aprendizagem do ponto de vista do estudante, solucionando-as.

A PPT encontra na Invenção Pedagógica referências para sua instauração por necessitar de reflexão na elaboração de soluções e, "além de exigir o "perder tempo" e a errância, ela envolve também, e de modo inelutável, um trabalho, uma repetição, uma disciplina, uma série de experiências, de exercícios e práticas que resultam na formação de hábitos e competências específicas" (KASTRUP, 2001, p. 24). Mais do que competência, a Invenção Pedagógica implica em conhecimento e na capacidade de criar algo com esse conhecimento, resolvendo problemas de aprendizagem de modo que todo o ato criativo pedagógico, tal como elaborar estratégias de 
ensino-aprendizagem, requer performance (MALLMANN, 2008). A Invenção Pedagógica depende da FTP para que a integração da tecnologia seja explorada pelos tutores, e vice-versa.

A PPT não corresponde a um modelo pronto e acabado de exercer tutoria. Por isso, a Invenção Pedagógica tem significativa importância. Além disso, um processo educativo inovador promove ações voltadas para o estudante e sua aprendizagem (PADILHA; BERAZA, 2016). Como processo complexo, a performance se instaura quando os tutores se abrem à transformação e a assumem como "um processo de autoformação e de criação transformadora" (CONTE, 2014, p. 543). Ela não é definida a priori e tem na Invenção Pedagógica uma condição necessária a sua instauração. A Invenção Pedagógica, na medida em que os tutores desenvolvem estratégias pedagógicas de acordo com as necessidades de aprendizagem, impede a formação de hábitos que possam tornar a Performance Pedagógica uma prática estática, mecânica e pré-estabelecida, sem reflexão e associação.

Ser inventivo no PEA significa ação e atualização, pois os tutores não têm uma rotina fixa e situações-problema surgem requerendo invenção na solução. Assim, a performance faz os tutores assumirem uma postura de pesquisadores, porque agir a partir das necessidades de aprendizagem exige pesquisa para supri-las. Inventar é criar novos procedimentos para resolução de problemas no PEA, novas ações, novas dinâmicas de mediação e Interação; é lidar com tecnologias diversas, materiais didáticos, conhecimentos e ideias como meios de invenção.

A Invenção Pedagógica não abrange somente o que é feito para a potencialização do PEA, mas a reinvenção do próprio modo de ser performer em Educação. Para Kastrup (2001), não há um método a ser adotado para criar na aprendizagem, mas uma política pedagógica que é a da invenção e que consiste em uma relação com o saber que não é de acúmulo nem de consumo de soluções, mas de experimentação e compartilhamento de problematizações e, também, de autoavaliação e autotransformação.

Integrar tecnologia transforma e alavanca o PEA de modo que "os estudantes sejam capazes de pensar de forma criativa, crítica e colaborativa para dominar os 'aspectos básicos' para se destacar [...] e para reagir às oportunidades e desafios com rapidez, agilidade e inovação" (TAPSCOTT, 2010). O conhecimento gerado pela FTP reverte em Invenção Pedagógica quando o tutor estabelece relação entre as dificuldades de aprendizagens com aquilo que pode ser feito com a tecnologia para solucioná-las. A invenção se dá no que se consegue inovar.

Nestas falas identificamos o que os tutores fazem no sentido da invenção: "Eu procuro buscar vídeos, textos, outros recursos"; "Um quesito bastante importante é buscar exemplos práticos a partir de vídeos para ampliar o conhecimento dos alunos, pois o vídeo prende a concentração, sendo mais atrativo que a leitura dos conteúdos". Os tutores indicam vídeos do Youtube para facilitar a compreensão dos conteúdos, mas isso vai além. Professores, tutores e estudantes também produzem vídeos de apresentação que são postados no Youtube e, depois, em um fórum no Moodle. Nesses vídeos, professoras e tutores se apresentam, falam como será a disciplina e se colocam à disposição dos estudantes; depois, os estudantes se apresentam falando no que atuam e do tema que pretendem pesquisar para o artigo final de curso. Os 
vídeos dos estudantes são comentados pelos tutores, com motivação e dicas sobre o tema de pesquisa escolhido.

A produção desses vídeos é uma estratégia inventiva que potencializa o PEA, aproximando professor, tutor e estudante. Aqui vemos, novamente, a necessidade da FTP, pois como o vídeo é postado no Youtube para, depois, inserir seu link no Moodle, alguns estudantes têm dificuldades nesse processo. Para auxiliar nisso, uma tutora diz que "a gente faz tutorial [...] faz um print e manda ou, então, executa a tarefa pro aluno, mostra como é, depois desfaz e faz ele fazer. Enfim, toda maneira possível a gente usa". Isso mostra o quanto a FTP é necessária para que o tutor possa ajudar o estudante a desenvolver a sua própria fluência.

Como outra estratégia, planilhas de controle de atividades também são produzidas no sentido da invenção, como nos relatou outra tutora dizendo que "a gente criou um sistema de tabelinha das atividades que todos os tutores acessam e a gente podia acompanhar quem estava fazendo, quem não estava, 'puxar a orelha' dos alunos [...] pra eles voltarem a fazer as coisas". Essas planilhas são feitas no Google Docs e compartilhadas entre professores e tutores para controlarem o andamento e avaliação das atividades.

As possibilidades inventivas procedem, também, por outras redes sociais, como no Facebook, conforme relato de uma tutora explicando que a Coordenação do curso criou um grupo nessa rede, onde Coordenação e tutores postam informações, como notícias da UAB/ UFSM, editais de seleção, datas de encontros presencias e de webconferências, links de livros PDF, dicas para a escrita do artigo final... Em alguns casos, esse grupo é usado para resgatar contato com estudantes infrequentes no Moodle, como disse essa tutora, afirmando que "em último caso, a gente manda mensagem por ali. [...]. Então a gente tenta tudo o que ta ao alcance, né". Nesse caso, há um conhecimento mais amplo da FTP, pois ao publicarem em uma rede social, demonstram o conhecimento de que essas informações podem ser utilizadas para diversas finalidades, como manter os estudantes informados e próximos do curso, que integrar redes sociais pode ser alternativa para recuperar contato de estudante, bem como a divulgação do curso para futuros interessados.

Ao integrar as redes sociais, o tutor amplia as possibilidades de Invenção Pedagógica e de Interação, agindo como um "artesão da cultura" e produzindo "uma nova cultura" (BERNAL, 2008) no ensino-aprendizagem. O modo de interagir com o estudante se contamina com esses outros meios que não tomam o lugar do Moodle, mas complementam a Interação e podem influenciar na continuidade de alguns estudantes no curso, por ser mais uma oportunidade por onde o tutor pode chegar até eles. Isso entra em consonância com a reposta de outro tutor quando questionado sobre o que faz para elaborar estratégias de ensino-aprendizagem, ao que respondeu que isso "implica buscar várias formas de interagir com os alunos, levando-se em conta as características pessoais de cada $[\ldots]$, fazendo com que o aluno se motive a estar constantemente envolvido com o curso".

A Invenção Pedagógica, em outros momentos, está em estratégias simples, como as relatadas nestas falas: "Indiquei o Google Acadêmico para os alunos pesquisarem mais coisas. [...] alguns não conheciam e puderam aumentar seus conhecimentos, não ficando só no material do Moodle" - aqui o tutor age, motivando o estudante com uma nova opção; "Costumo 
fazer tutoriais com imagens ou gravar algum áudio para explicar e fazer o aluno compreender" - nesse caso, além de interagir com áudio, a criação desses tutoriais constituem um passo-apasso com imagens e explicações sobre determinado procedimento a ser feito com alguma tecnologia, são meios explicativos que requerem capacidade de síntese e organização; "Uso uma tabela de acompanhamento que está no Google Drive [...]. Costumo acompanhar os alunos semana a semana, de acordo com a tabela. [...] adotei uma política de zero e-mail, ou seja, todos os dias faço uma triagem nos e-mails" - nessa situação temos um modo próprio de monitoramento elaborado pelo tutor; "[...] quando indica alguma tecnologia ou alguma coisa que ajuda os alunos além do que foi postado no Moodle [...] quando o tutor mostra outras opções" - aqui, 'mostrar outras opções' remete a ideia de pesquisa, como na indicação de materiais além do que consta na Moodle, o que faz o tutor pesquisar para saber o que indicar ao estudante que, por sua vez, pesquisa no material indicado. Isso faz a pesquisa permitir a transformação, a intervenção e a produção de conhecimento.

Dito isso, vemos que os tutores pesquisam alternativas para além do que o Moodle oferece, como possibilidades de Invenção Pedagógica. Quando implementam essas estratégias, desenvolvem a Performance Pedagógica, tendo o ensino-aprendizagem como preocupação primeira. A pesquisa é necessária para haver inovação e atualização, o que percebemos na fala de um tutor ao afirmar que "estudo metodologias ativas de aprendizagem, a partir de artigos que trazem sua relação com cursos a distância ou da UAB". A atualização por meio do estudo de temas atuais gera competências na PPT, não se resumindo em mero somatório de atividades e atribuições, embora isso se inclua, pois a reflexão e a elaboração de estratégias pedagógicas, do mesmo modo, se incluem. Nesse sentido, a PPT engloba o que os tutores fazem para tornar o PEA mais inventivo, estando aí imbricada a Interação.

\subsection{Interação}

A Interação entre professores, tutores e estudantes é a oportunidade para que a Invenção Pedagógica aconteça. É na Interação que ideias e possibilidades surgem como propulsoras de transformação e intervenção, resultando em invenção e produção de conhecimento. Para haver invenção, é necessário conhecer o estudante, observar seus comportamentos e estabelecer diálogos, o que requer Interação como "um campo de criação, uma zona de vizinhança, um espaço híbrido" (KASTRUP, 2001, p. 25), ou seja, como o espaço-oportunidade que subsidia a invenção. Os tutores assumem, assim, um caráter empático ao interagirem e implementarem estratégias pedagógicas com as quais a Performance Pedagógica transforma, intervém e se adapta, acolhendo a voz do estudante.

Na EAD, a Interação integra comunicação e enunciação. Penteado (2015) defende a esfera digital como viabilizadora de um novo modo de enunciação, no qual o tutor transmite uma postura ética pelo seu discurso que possui aspecto e função, ambos estéticos nos AVEA. Esse discurso ocorre, basicamente, pela escrita. Para Kenski (2002, p. 248):

Interagir com o conhecimento e com as pessoas para aprender é fundamental. Para a transformação de um determinado grupo de informações em conhecimentos é preciso que estes sejam trabalhados, discutidos, comunicados. As trocas entre colegas, os múltiplos posicionamentos diante das 
informações disponíveis, os debates e as análises críticas auxiliam a sua compreensão e elaboração cognitiva.

Para Biancalana (2012), o performer (o tutor neste estudo) precisa de um aprimoramento técnico-expressivo comunicativo que implica estabelecer modos interativos que agilizem e potencializem a PPT. Os tutores estabelecem um processo interativo com os estudantes, cuja finalidade é o sucesso do PEA e, por isso, a Interação precisa ser embasada nos conhecimentos que os estudantes adquirem ao longo das suas experiências e, principalmente, nos conteúdos curriculares (JACQUES, 2014).

Na PPT, a Interação abre a oportunidade da colaboração entre os tutores, de modo que o conhecimento se construa a partir de ações mútuas e compartilhadas. É durante a Interação que carências no PEA são identificadas e solucionadas colaborativamente. A troca de mensagens, entre tutor e estudante, é algo que proporciona Interação e diálogoproblematizador, sendo este "o encontro em que se solidariza o refletir e o agir de seus sujeitos endereçados ao mundo a ser transformado e humanizado, não pode reduzir-se a um ato de depositar ideias de um sujeito no outro" (FREIRE, 1987, p. 45). Esta conduta favorece a problematização, potencializando o PEA. O diálogo permite aprender em conjunto, sendo que a Interação se opõe à individualidade na tutoria da UAB/UFSM. Nesse contexto, as tecnologias oferecem condições para que o PEA tenha na Interação a potencialização da PPT.

Nos questionários, nas observações e na entrevista obtivemos depoimentos que nos levaram a Interação como outro princípio da tutoria. Selecionamos, a seguir, alguns fragmentos que nos convenceram disso:

\footnotetext{
"... fazer aquela nossa parte que é da mediação".

"A principal atribuição do tutor é a de mediar a comunicação entre o aluno e o professor, o conteúdo e tudo mais que envolve o curso".

"... mediar a relação e interação aluno-professor".

"Acredito que, principalmente, ser o elo entre professor e o aluno e a ferramenta".

"Também tento ter uma relação bem próxima deles, utilizando uma linguagem amigável e aberta para comunicação".

"Trocamos informações constantemente, nos comunicamos diariamente."

"À medida que a interação tutor/aluno avança é possível perceber as carências dos alunos e, a partir de então, direcionar o foco para suprir essa necessidade".

"... o tutor é um pouco mais envolvido, implicado no dia a dia dos estudantes, ele cria um vínculo muito forte".
}

Com base nessas respostas, a mediação e a comunicação são o que integra professores, tutores, estudantes, conteúdos, materiais didáticos, recursos tecnológicos e o Moodle, criando o vínculo que só é possível quando a Interação se estabelece. Quando uma tutora relatou que em atividades de fóruns, os estudantes devem "comentar a resposta de algum colega e o colega tem que dar o retorno, pra ter o bate e volta, [...] a gente vai lá e dá aquela conversada, questiona [...] pra instigar o debate", ela está interagindo com os estudantes, fazendo-os interagir entre si e estabelecendo os vínculos que oportunizam colaborarem e expressarem suas palavras. A Interação corresponde, portanto, a um envolvimento com tudo o que integra a PPT, sendo o tutor o elo que estabelece relações dialógicas pautadas na mediação e na comunicação entre todos, cumprindo com sua empatia e não indiferença para com as necessidades dos estudantes. Nesse sentido, um tutor diz que "os alunos nos pedem para 
mediar comunicações com a Coordenação e com os professores e vejo que isso de fato funciona, pois algumas solicitações dos alunos só são atendidas quando o tutor está envolvido. É uma questão de confiança".

A Interação acontece engajada à FTP e à Invenção Pedagógica, envolvendo um trabalho que é em equipe. Para os tutores, a Interação deve ser constante e o contato, mesmo a distância, deve ser próximo, ocorrendo, basicamente, por mensagens, fóruns e e-mails, sendo a linguagem escrita a base da Interação. Daí a necessidade de os tutores se comunicarem textualmente com clareza, cordialidade e empatia, gerando aproximação com resolução de conflitos e dúvidas. A escrita torna-se a "voz" na Interação quando monitoram, supervisionam, auxiliam e acompanham os estudantes. Interagir por meio das TER é ser e fazer a distância. É ser e agir através da escrita, linguagem com a qual o tutor enuncia-se no espaço digital (PENTEADO, 2015). O modo como os tutores se pronunciam nos seus discursos escritos pode instigar a reflexão e a pesquisa, delimitando as particularidades da Interação na PPT.

\section{Considerações finais}

Embasados no estudo realizado, constatamos que a Performance Pedagógica dos Tutores (PPT) da UAB/UFSM solicita Fluência Tecnológico-Pedagógica (FTP), Invenção Pedagógica e Interação, sendo estes seus princípios. Entendemos a tutoria na Educação a Distância (EAD) como lócus de uma Performance Pedagógica que, por meio das Tecnologias Educacionais em Rede (TER), encontra potencial para o Processo Ensino-Aprendizagem (PEA) que se alicerça nos respectivos princípios. A exploração do potencial tecnológico desenvolve a FTP, o que permite a Invenção Pedagógica e a Interação, e vice-versa. Verificamos que os tutores, ao estabelecerem relações entre as necessidades do ensino-aprendizagem com aquilo que pode ser feito com as tecnologias para supri-las, potencializam o PEA em uma perspectiva inventiva e interativa, e isso caracteriza a PPT. Portanto, a Invenção Pedagógica e a Interação dependem da FTP, estando esses três princípios imbricados entre si.

A PPT é o movimento de realização de um conjunto de estratégias pedagógicas que integram, caracterizam e atribuem sentidos ao agir, ao movimento de ação-reflexão-ação do tutor, é o modo como conduz e promove o PEA; é o que o tutor realiza pedagogicamente na sua função, não sendo apenas operacionalização e conhecimento teórico e prático, pois seus valores, modos de ser, fazer, agir e pensar se interconectam, integrando sua performance. Não é sinônimo de prática pedagógica, não é desempenho, nem somente o lado prático do fazer. A PPT inclui ação, fazer e movimento de ensinar e aprender. Por isso, é algo acontecendo. Os princípios da FTP, da Invenção Pedagógica e da Interação potencializam a PPT que, por sua vez, embasa e alavanca o PEA, produzindo conhecimento, transformação e intervenção. Nisso, consiste a complexidade da PPT da UAB/UFSM.

A PPT é um movimento realizado pelos tutores que dá forma ao modo de exercer a tutoria, com características próprias vindas da FTP, da Invenção pedagógica e da Interação com professores, estudantes tecnologias e materiais didáticos. Nesse movimento, a PPT engloba um conjunto formado pelas atitudes dos tutores, seus atos e inquietações, escritas e falas, pesquisas e estudos, erros e acertos. 
Dito isso, e dado o amplo campo de possibilidades que a Educação tem a oferecer aos estudos da PPT, futuras pesquisas são tão possíveis quanto necessárias. Portanto, investir em problematizações sobre a PPT, no ensino superior a distância, é potencializar e ampliar as possibilidades de o PEA, embasado na FTP, na Invenção Pedagógica e na Interação, promover transformação, intervenção e produção de conhecimento.

\section{Referências}

AMARAL, S. F. do; AMIEL, T. Nativos e imigrantes: Questionando o conceito de Fluência Tecnológica Docente. Revista Brasileira de Informática da Educação, Campinas, SP, v. 21, n. 3, p. 1-11, dez. 2013. Disponível em: <http://www.br-ie.org/pub/index.php/rbie/article/view/1661>. Acesso em 21 set 2017.

BERNAL, E. G. Formação do tutor para a educação a distância: fundamentos epistemológicos. EccoSRevista Científica, São Paulo, v. 10, n. 1, p. 55-88, jan/jun, 2008. Disponível em: < http://www.redalyc.org/ articulo.oa?id=71510104>. Acesso em: 18 jul 2017.

BIANCALANA, G. R. Performatividade: presença cênica e elementos culturais. Anais do VII Congresso da ABRACE- Tempos de Memória: Vestígios, Ressonâncias e Mutações-Porto Alegre-Outubro 2012.

CONTE, E. Aporias da performance na educação. 2012. 283 f. Tese (Doutorado em Educação) - Programa de Pós-Graduação em Educação, Universidade Federal do Rio Grande do Sul, Faculdade de Educação: Porto Alegre, 2012.

CONTE, E. Tempo e performance no trabalho docente. Revista Educação, Santa Maria, v.39, n.31, p. 541-552, set./dez. 2014. Disponível em: <https://periodicos.ufsm.br/reveducacao/article/view/14250/ pdf>. Acesso em: 15 out 2017.

CORRÊA, J. Sociedade da informação, globalização e educação a distância. Rio de Janeiro: Senac, 2005.

FREIRE, P. Pedagogia do oprimido. Rio de Janeiro: Paz e Terra, 1987.

GIL, A. C. Estudo de caso. São Pulo: Atlas, 2009.

ICLE, G. Da performance na educação: perspectivas para a pesquisa e a prática. In: PEREIRA, M. de A. (org). Performance e Educação: (des)territorializações pedagógicas. Santa Maria: Ed. da UFSM, 2013.

JACQUES, J. S. Performance multidisciplinar nas ações de pesquisa, desenvolvimento e capacitação:produção de materiais didáticos hipermidiáticos no Moodle. 2014. 244 f. Dissertação (Mestrado em Educação)-Universidade Federal de Santa Maria, Santa Maria, RS, 2014.

KASTRUP, V. Aprendizagem, arte e invenção. Psicologia em Estudo, Maringá, v.6, n.1, p. 17-27, jan./jun. 2001. Disponível em: <http://www.scielo.br/pdf/pe/v6n1/v6n1a03.pdf>. Acesso em: 07 out 2017.

KENSKI, V. M. Processos de interação e comunicação mediados pelas tecnologias. In ROSA, D.; SOUZA, V. (orgs). Didática e práticas de ensino: interfaces com diferentes saberes e lugares formativos. Rio de Janeiro: DP\&A, 2002.

MALLMANN, E. M. Mediação Pedagógica em Educação a Distância: cartografia da performance docente no processo de elaboração de materiais didáticos. 2008. 304 f. Tese (Doutorado em Educação) - Programa de Pós-Graduação em Educação, Universidade Federal de Santa Catarina: Florianópolis, 2008.

MALLMANN, E. M.; CATAPAN, A. H. Performance docente na mediação pedagógica em educação a distância. Inter-Ação, Goiânia, v. 35, n. 2, p. 359-372, jul/dez, 2010. Disponível em: <https://www.revistas.ufg.br/ interacao/article/download/13128/8524>. Acesso em: 18 set. 2017.

MALLMANN, E. M. et al. Guia de Tutores UAB/UFSM. Santa Maria: UFSM, 2011.

MALLMANN, E. M. et al. Ensino-aprendizagem mediado por tecnologias em rede: complexidade da performance docente. Revista Reflexão e Ação, Santa Cruz do Sul, v.21, n.2, p. 309-334, jul./dez. 2013. Disponível em: <http://online.unisc.br/seer/index.php/reflex>. Acesso em: 15 out 2017.

MALLMANN, E. M.; SCHNEIDER, D. R.; MAZZARDO M. D. Fluência tecnológico-pedagógica (FTP) dos tutores. RENOTE Novas Tecnologias na Educação, UFRGS, Porto Alegre, v. 11, n. 3, 2013. Disponível em: <http://seer.ufrgs.br/index.php/renote/article/view/44468>. Acesso em: 10 out 2017. 
MALLMANN, E. M.; JACQUES, J. S. Design pedagógico de materiais didáticos: performance docente na produção hipermidiática em ambientes virtuais. FAEEBA - Educação e Contemporaneidade, Salvador, v. 23, n. 42, p. 49-64, jul./dez. 2014. Disponível em: <https://www.revistas.uneb.br/index.php/faeeba/article/ view/1047>. Acesso em: 10 out 2017.

MALLMANN, E. M.; JACQUES, J. S. Recurso Didático Digital: complexidade da performance docente na produção (hiper)textual. Texto Digital, Florianópolis, Santa Catarina, Brasil, v. 11, n. 2, p. 53-70, jul./dez. 2015. Disponível em: <https://periodicos.ufsc.br/index.php/textodigital/article/view/ 1807-9288.2015v11n2p53>. Acesso em: 28 set 2017.

MORAES, R.; GALIAZZI, M. do C. Análise textual discursiva. Ijuí: Unijuí, 2013.

PADILHA, M. A. S.; BERAZA, M. A. Z. Um cenário de integração de tecnologias digitais na educação superior: em busca de uma coreografia didática inovadora. Revista e-Curriculum, São Paulo, v. 14, n. 03, p. 837-863, jun/set 2016. Disponível em: <http://revistas.pucsp.br/index.php/curriculum/article/view/ 28698>. Acesso em: 18 set 2018.

PENTEAdO, M. T. L. A Polifonia no Discurso Pedagógico do Tutor. Revista Científica em Educação a Distância - EAD em Foco. Rio de Janeiro, v. 5, n. 3, 2015. Disponível em: <http://eademfoco.cecierj.edu.br/ index.php/Revista/article/view/258>. Acesso em: 12 ago 2018.

PEREIRA, M. de A. Performance e educação: relações, significados e contextos de investigação. Educação em Revista, Belo Horizonte, vol. 28, n.1, p. 289-312, mar. 2012. Disponível em: <http://dx.doi.org/ 10.1590/S0102-46982012000100013 > . Acesso em: 17 jan 2018.

PEREIRA, M. de A. (org). Performance e Educação: (des)territorializações pedagógicas. Santa Maria: Ed. da UFSM, 2013.

SALGADO, T. B. P. Perfomance. Dispositiva - Revista do programa de Pós-Graduação em Comunicação Social da faculdade de Comunicação e Artes da PUC Minas, v.2, n.2, p. 74-90, 2014: (novembro 2013junho 2014). Disponível em: <http://periodicos.pucminas.br/index.php/dispositiva/article/view/7627/0>. Acesso em: 12 out 2017.

SCHECHNER, R.; ICLE, G.; PEREIRA, M. de A. O que pode a performance na educação? Uma entrevista com Richard Schechner. Educação \& Realidade, v. 2, n. 35. p. 23-35, maio/ago 2010. Disponível em: <https://seer.ufrgs.br/educacaoerealidade/article/view/13502>. Acesso em: 4 out 2017.

SCHRAIBER, R. T.; MALLMANN, E. M. Performance pedagógica de tutores na educação a distância. REVEDUC, Revista Eletrônica de Educação-Universidade Federal de São Carlos, v. 12, n. 3, p. 757-775, set/ dez. 2018a. Disponível em: <http://www.reveduc,ufscar.br/index.php/reveduc/article/view/2469/734>. Acesso em: 11 out 2018

TAPSCOTT, D. A hora da geração digital: como os jovens que cresceram usando a internet estão mudando tudo, das empresas aos governos. Rio de Janeiro: Agir Negócios, 2010.

Recebido em outubro de 2018

Aprovado para publicação em dezembro de 2018

\section{Rogério Tubias Schraiber}

Doutorando em Educação - Universidade Federal de Santa Maria, UFSM, Brasil

rogerio@cead.ufsm.br

\section{Elena Maria Mallmann}

Professora do Programa de Pós-Graduação em Educação - Universidade Federal de Santa Maria, UFSM, Brasil

elena.ufsm@gmail.com 